\title{
Observations on the Brain of the Coelacanth Latimeria chalumnae: External Anatomy and Quantitative Analysis
}

R. GLENN NORTHCUTT, ${ }^{1}$ TIMOTHY J. NEARY ${ }^{1.3}$ AND DAVID G. SENN ${ }^{2}$ ${ }^{1}$ Division of Biological Sciences, University of Michigan, Ann Arbor, Michigan 48109; and ${ }^{2}$ Zoologische Anstalt, Universität Basel, Basel, Switzerland

\begin{abstract}
New data on the brain of Latimeria indicate that previous estimates of the brain weight were too high by a factor of two. Our data suggest a brain weight of 1.1-1.5 grams for a specimen with a body weight of 30 kilograms. Quantitative data on major divisions of the brain are presented for the first time, and the relative size of the major brain divisions is similar to that of sturgeons and generalized sharks (such as hexanchids and squalids). Examination of brain component weight(s): body weight plots in a sample of non-teleost actino. pterygian fishes indicates that all major divisions of the brain, except the telencephalon, are larger than in Latimeria. Brain component sizes in Latimeria are more similar to those extrapolated for amphibian brains than to those for actinopterygians. However, the cerebellum of Latimeria is considerably larger than that of amphibians.
\end{abstract}

Coelacanths, thought to be extinct since the late Cretaceous, were known only from the fossil record prior to 1938 when J. L. B. Smith described the first living specimen. The anatomy of Latimeria is particularly interesting to evolutionary biologists because this species appears to be the sole living representative of the Crossopterygii, a group of bony fishes that gave rise to land vertebrates. More than 70 Latimeria have been captured during the last 30 years. Millot and Anthony, in particular, have devoted several years to investigating the general anatomy of these specimens and have reported on this work in several monographs. The nervous system has received their attention as well (Millot and Anthony, '56, '65, '67); however, to our knowledge, the only detailed illustration and description of the external anatomy of the brain of Latimeria is that of Millot and Anthony ('65) in which the brain is figured with meninges and blood vessels intact. These tissues are so extensive that little detail of the actual brain surface can be recognized.

An international expedition, resulting from French, British and American cooperation, captured a live coelacanth in March, 1972, and immediately dissected and preserved tissues. We were fortunate to receive the brain of this specimen, thus allowing us to report details of the external anatomy of the brain of Latimeria and to compare the brain with those of other vertebrates. This report also includes the first quantitative measurements on major divisions of the Latimeria brain. Our comparisons are primarily phenetic rather than phylogenetic due to the paucity of comparative studies, particularly experimental studies, on the brains of bony fishes. Far more information is needed on the brains of these forms before neural trends and their polarity can be established. We have excluded the brains of teleosts, as well as those of amniotic vertebrates, from comparison with Latimeria because they are distinctly different from Latimeria and the other fishes.

\section{MATERIALS AND METHODS}

Three specimens of Latimeria were available for our study. Specimens 1 and 2 were provided by the Field Museum of Natural History in Chicago, and no locality or museum numbers are available. The brain of specimen 1 was removed in 1969 by RGN and prepared in serial cross sections by the Bodian method. Specimen 2 was a male with a total length of

\footnotetext{
${ }^{3}$ Present address: Department of Anatomy, Creighton University, Omaha, Nebraska 68178.
} 
$128 \mathrm{~cm}$ and a preserved body weight of $30 \mathrm{~kg}$. Both specimens were initially preserved in $10 \%$ formalin, then stored in $70 \%$ ethanol. Following excision, the brains were stored in AFA ( $80 \%$ ethanol: $100 \%$ formalin:glacial acetic acid; 90:5:5). Neither brain was adequately fixed for histology, but they did allow examination of the origin and intracranial course of the cranial nerves.

Specimen 3 was caught at Iconi, Grande Comoro on March 22, 1972, under the auspices of the French-British-American expedition. The brain was removed shortly after death and immersed in a gluteraldehyde EM fixative (Locket, '73). This specimen was an immature female with a total length of $85 \mathrm{~cm}$. Unfortunately, no body weight was recorded.

The illustrations of external brain anatomy, by camera lucida and graphic reconstruction methods, are based on both specimens 2 and 3 , as each was partly damaged prior to our receipt. After analysis of the external anatomy, the brain of specimen 2 was divided into the following components for weighing: olfactory bulbs, telencephalic hemispheres (including olfactory peduncles), diencephalon, mesencephalon, cerebellum, and medulla. The caudal boundary of the telencephalon was considered to be a plane extending from the rostral border of the habenular nuclei to the rostral border of the optic chiasm. The caudal boundary of the diencephalon was considered to be a plane extending from the rostral pole of the optic tectum to the caudal pole of the infundibulum. The optic nerves were not included in the weight of the diencephalon, but were transected within $2 \mathrm{~mm}$ of the chiasm. The cerebellum was considered to include all tissue lying dorsal to a rostro-caudal transection just below the ventral lip of the cerebellar auricle. The caudal boundary of the medulla was set at the level of the first complete cervical spinal nerve. All cranial nerves were transected at the base of the brain, and neither they nor the meninges, blood vessels or choroid plexus of the fourth ventricle were included in the brain division weights.

Measurements of the brain divisions of specimen 2 contain a sizable error factor, as this brain was badly desiccated and shrunken at excision. The same series of measurements could not be performed on brain specimen 3 because the olfactory bulbs, part of the olfactory peduncles, and the dorsal half of the epithalamus had been removed prior to our re- ceiving the brain. However, these parts contribute only slightly to the total brain weight (fig. 4). Therefore, the weighing of brain specimen 3 , with its meninges, blood vessels, and choroid plexus of the fourth ventricle removed, allowed us to estimate a correction factor for the shrinkage of the brain of specimen two. To form another basis for estimating a correction factor, we transected brain specimen three at the mesen-cerebellar junction and recorded the combined weight of the cerebellum and medulla. We did not perform any finer dissection of brain specimen three because of its histological value. Finally, brain specimen three was sectioned in the transverse plane for histological analysis and was used to check our initial determination of cra. nial nerves.

For comparison, brains from a number of vertebrate species (table 1) were fixed in situ in AFA. All specimens were adults based on gonadal tissue and reported adult body lengths. Following fixation, the brains were divided and weighed according to the criteria established for Latimeria. Data reported in table 1 are based on a single specimen of each species. Six specimens of Necturus were measured to assess intraspecific variation in brain weight. Their body weights ranged from 103$131 \mathrm{gm}$, and the mean brain weight was 0.1068 $\mathrm{gm}$ with a S.E. of $3.9 \%$. The reliability of our comparisons might be improved by increasing the number of species, particularly amphibians, examined; however, our coefficients of allometry for urodele brain divisions closely agree with those in the extensive study of Thireau ('76) who examined 43 species of urodeles.

Brains of the species being compared to Latimeria were first fixed in AFA because unfixed neural tissue is almost impossible to manipulate without considerable distortion. Fixation in AFA results in an $8-9 \%$ reduction in brain weight, and the brain division weights reported are not corrected for this reduction.

Fig. 1 Dorsal view of the brain of Latimeria. Olfactory bulbs of the telencephalon not pictured. a lat, anterior lateral line nerve; au, auricle of cerebellum; ce, corpus of cerebellum; cer, cervical spinal nerve; inf, infundibulum of the hypothalamus; obl, medulla oblongata; occ, occipital (hypoglossal) nerves; on, optic nerve; op, olfactory peduncle (tract); p lat, posterior lateral line nerve; pit, pituitary gland; tec, optic tectum; tel, telencephalon; III, oculomotor nerve; IV, trochlear nerve; $V_{1}$, profundus nerve; $V_{2.3}$, trigeminal nerve; VI, abducent nerve; VII, facial nerve; VIII, acoustico-vestibular nerve; IX, glossopharyngeal nerve; $\mathbf{X}$, vagus nerve. 


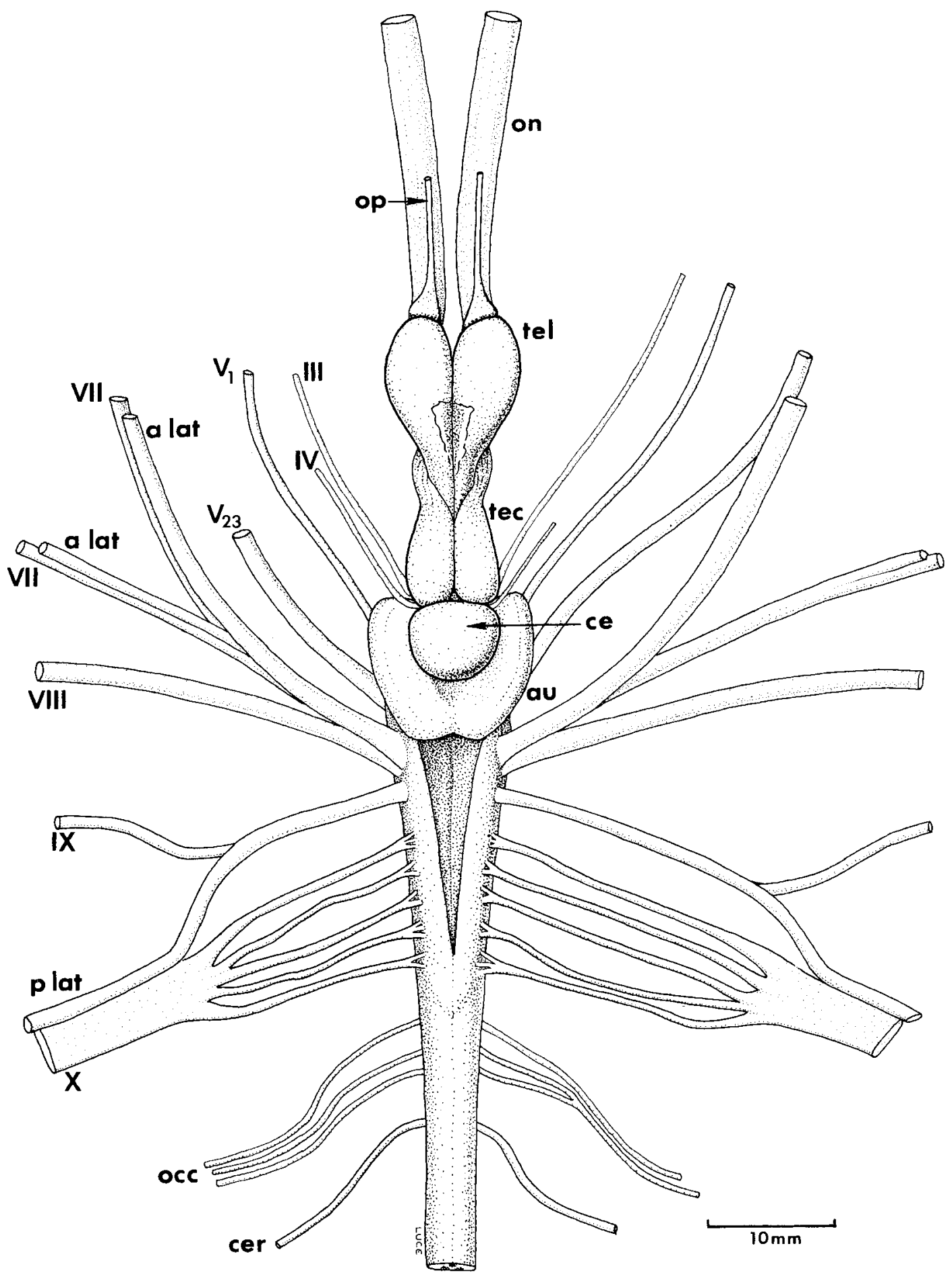

Figure 1 
TABLE 1

Brain weight: body weight data

\begin{tabular}{|c|c|c|c|c|c|c|c|c|}
\hline Species & $\begin{array}{c}\text { Body } \\
\text { weight } \\
\text { in kg }\end{array}$ & $\begin{array}{c}\text { Brain } \\
\text { weight } \\
\text { in } \mathrm{gm}\end{array}$ & \multicolumn{6}{|c|}{ Brain component weights in gm } \\
\hline Ambystoma maculatum & 0.022 & 0.0328 & 0.0033 & 0.0143 & 0.0057 & 0.0018 & 0.0009 & 0.0068 \\
\hline Ambystoma tigrinum & 0.040 & 0.0590 & 0.0073 & 0.0252 & 0.0079 & 0.0042 & 0.0010 & 0.0134 \\
\hline Amia calva & 0.727 & 0.3485 & 0.0330 & 0.0707 & 0.0424 & 0.0841 & 0.0288 & 0.0895 \\
\hline alleganiensis & 0.400 & 0.1611 & 0.0242 & 0.0606 & 0.0153 & 0.0090 & 0.0020 & 0.0500 \\
\hline Dicamptodon ensatus & 0.052 & 0.0760 & 0.0082 & 0.0259 & 0.0098 & 0.0087 & 0.0011 & 0.0223 \\
\hline Hyla septrionalis & 0.014 & 0.0474 & 0.0050 & 0.0150 & 0.0066 & 0.0085 & 0.0008 & 0.0115 \\
\hline Latimeria chalumnae & 30 & 1.2596 & 0.0320 & 0.3014 & 0.1176 & 0.1316 & 0.2200 & 0.4570 \\
\hline Rana catesbeiana & 0.427 & 0.2178 & 0.0200 & 0.0476 & 0.0345 & 0.0556 & 0.0046 & 0.0555 \\
\hline $\begin{array}{l}\text { Rana pipiens } \\
\text { Scaphirhynchus }\end{array}$ & 0.035 & 0.1019 & 0.0068 & 0.0277 & 0.0137 & 0.0233 & 0.0019 & 0.0285 \\
\hline platorynchus & 0.510 & 0.2362 & 0.0314 & 0.0291 & 0.0469 & 0.0326 & 0.0254 & 0.0708 \\
\hline Sphyrna lewini & 55.71 & 59.880 & 4.1916 & 31.1376 & 2.3952 & 3.5928 & 11.3772 & 7.1856 \\
\hline Squalus acanthias & 1.252 & 2.9377 & 0.2365 & 0.6242 & 0.2679 & 0.4977 & 0.6170 & 0.6944 \\
\hline
\end{tabular}

Each brain was dissected while immersed in the fixative, and each brain part was blotted immediately prior to weighing on a Mettler analytical balance (Model H10). The accuracy of ten repeated measurements on the smallest brains $(0.03 \mathrm{~g})$ was $\pm 0.3 \%$; while accuracy on small brain divisions $(0.003 \mathrm{~g})$ was $\pm 1.6 \%$. Recorded body weights are from fresh material.

\section{RESULTS}

\section{General observations}

The brain of Latimeria is considerably elongated with little trace of the cephalic flexures seen in most bony fishes except dipnoans. As Millot and Anthony ('65) noted, the brain is housed in an expansive neurocranium, and a centimeter or more of the peripheral course of most of the cranial nerves is observable within the neurocranium.

The olfactory peduncles (figs. 1-3) are extremely long, and the olfactory bulbs are directly apposed to the nasal cavity. The swellings at the rostral poles of the telencephalic hemispheres do not represent the olfactory bulbs. This was determined at the time of dissection and confirmed by subsequent histolog. ical examination. In this respect Latimeria clearly differs from the lepidosirenid lungfishes in which the olfactory bulbs arise from, and are in direct continuity with, the telencephalon. Elongated peduncles also occur in some actinopterygians and in most cartilaginous fishes, as well as in Neoceratodus.

The telencephalon of Latimeria is relatively longer than that of actinopterygian fishes with the exception of Polypterus (Nieuwenhuys, '69; Braford and Northcutt, '74), and its shape is more similar to the telencephalon in dipnoans. The general similarity is further reinforced by an obvious lateral swelling of the ventral telencephalon (figs. 2,3 ) which is even more pronounced in the Dipnoi (Holmgren and van der Horst, '25; Nieuwenhuys, '69; Clairambault and Capanna, '73; Northcutt, '77a).

The pituitary of Latimeria appears unique among that of vertebrates we have examined, as it extends rostrally rather than caudally from the infundibulum. This condition, noted previously (Millot and Anthony, '65; Nieuwenhuys, '69), has been interpreted as a consequence of skull growth rapidly out-distancing brain growth and the rostral shifting of the hypophyseal fenestra.

The optic nerves are large and appear relatively larger than do those of most bony fishes. They are far larger than those of any of the living dipnoans (Holmgren and van der Horst, '25; Schnitzlein and Crosby, '68). The optic tectum is clearly paired and possesses slightly developed lateral recesses and well developed cellular and fibrous laminae (Northcutt and Neary, '75). The internal organization of the 


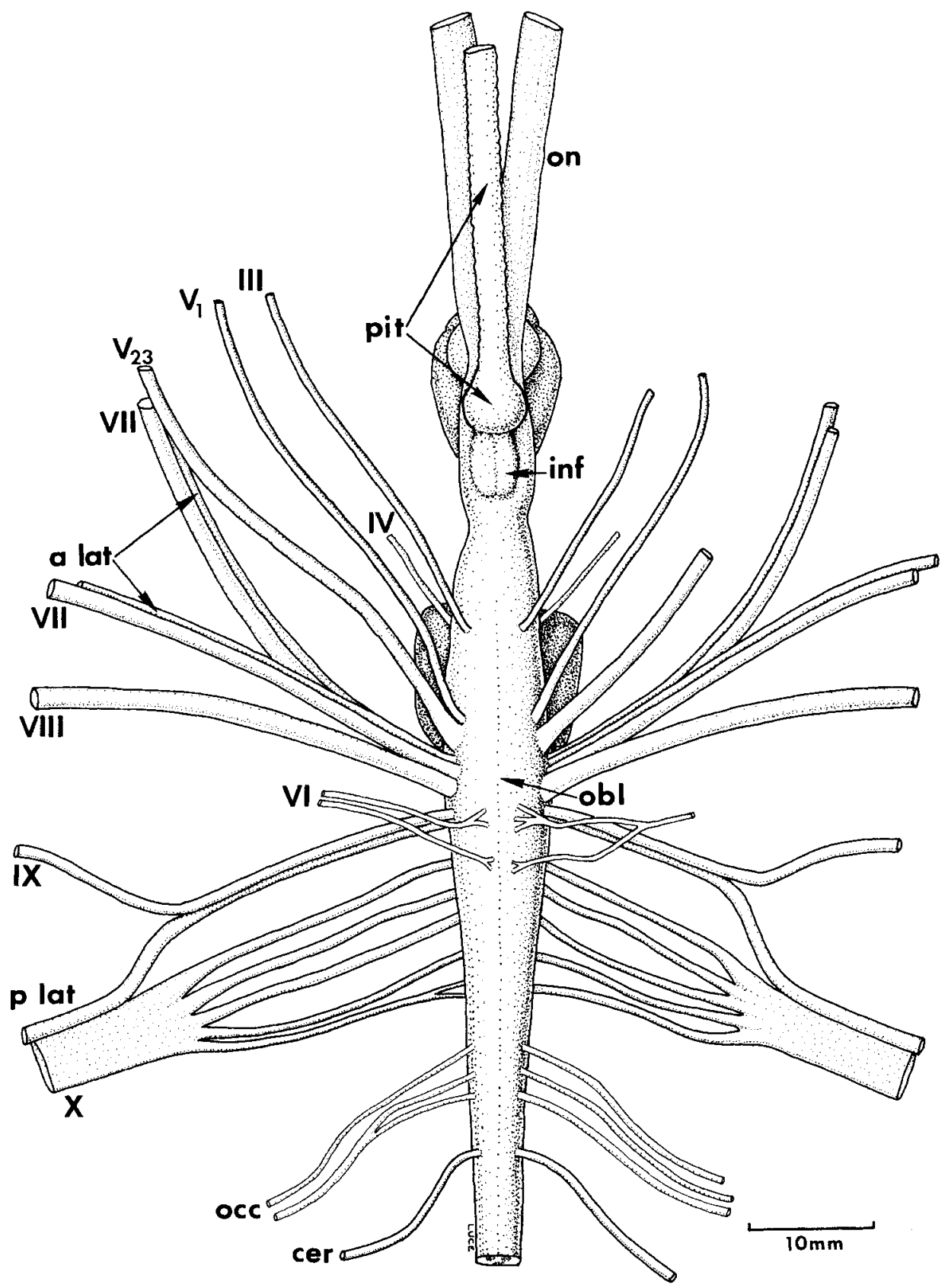

Fig. 2 Ventral view of the brain of Latimeria. Abbreviations same as figure one.

tectum of Latimeria reveals more extensive differentiation than the tecta of dipnoans and salamanders (Holmgren and van der Horst, '25; Herrick, '48; Northcutt, '77a).

The large cerebellum (figs. 1-3) is the most striking feature of the general morphology of the Latimeria brain. The corpus is a large spherical dome surrounded laterally and caudally by pronounced auricles, and the cerebellum is larger than in living amphibians. 


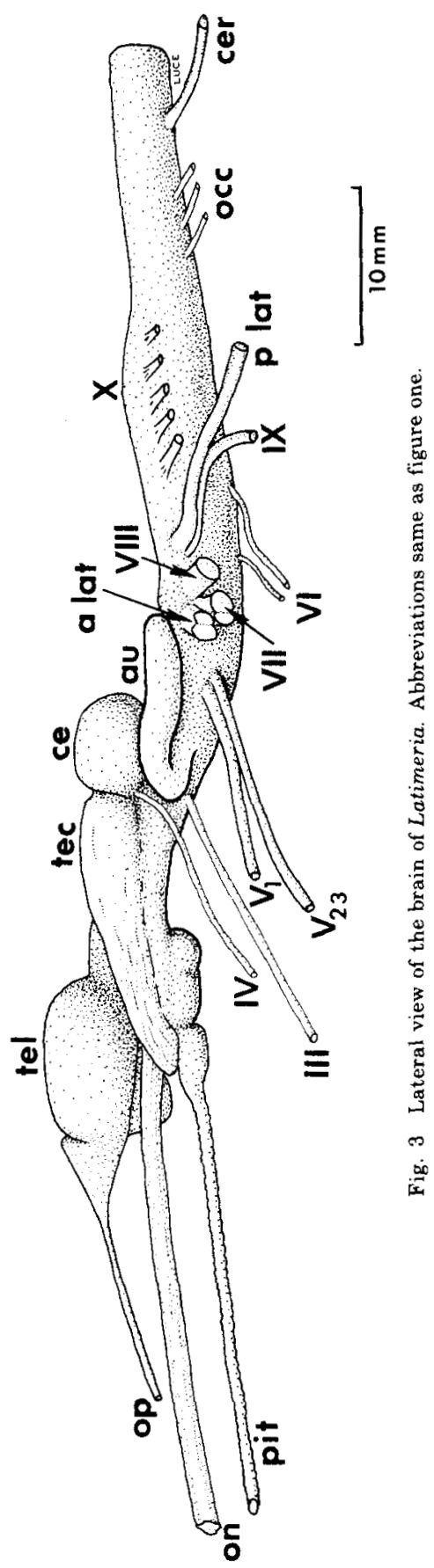

Latimeria has all three somatic motor cranial nerves, innervating the extrinsic eye muscles; and they arise from the same brain stem areas as in other vertebrates. The abducent nerve is unusual as it arises from multiple roots, and the most caudal ramus is considerably removed from the other rami (fig. 2).

Latimeria, like other bony fishes, possesses a distinct profundus branch $\left(\mathrm{V}_{1}\right)$ of the trigeminal complex. However, $V_{1}$ separates very proximally from the mandibular and maxillary branches $\left(V_{2.3}\right)$. The facial cranial nerves are obvious and divide into rostral and caudal branches (figs. 1-3). Both branches are closely associated with branches of the anterior lateral line nerves in their course toward neurocranial exit. However, the anterior lateral line nerves are distinct cranial nerves possessing separate entry into the medulla dorsal to the facial rami (fig. 3).

The eighth cranial nerves consist of a single ramus with entry caudal to the anterior lateral line nerves (fig. 3), Latimeria is similar in this respect to most other bony fishes.

The posterior lateral line nerves are well developed and are first seen in close association with the vagal nerves as they enter the neurocranium (figs. 1, 2). However, the posterior lateral line nerves rapidly arc rostrally and run with the glossopharyngeal nerves. In Latimeria there can be no question that the anterior and posterior lateral line nerves are distinct and separate cranial nerves. These lateral line nerves are clearly not components of the facial and vagal nerves, even though they have frequently been said to be components of these branchiomeric nerves (see Goodrich, ' 58 for general review).

The vagal nerves are well developed and, as in other vertebrates, arise from a series of rootlets (figs. 1-3). Latimeria, like other bony fishes, possesses a number of spino-occipital nerves which innervate the hypobranchial musculature and are probably homologous to the hypoglossal nerves of land vertebrates.

\section{Qualitative observations}

In figure 4 , the relative size of the major brain divisions of Latimeria is compared to that of other vertebrates. Brains most like that of Latimeria are located in adjacent columns, while those most different are clustered to the right side of the figure. The brain of Latimeria is most similar to those of gen- 


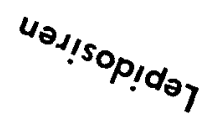

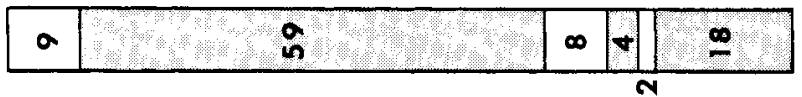

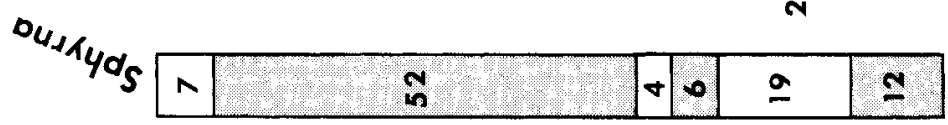

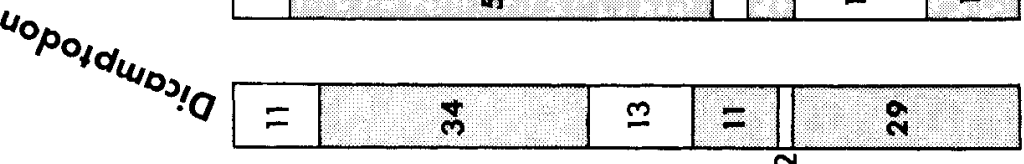

$0_{1} n_{8}$
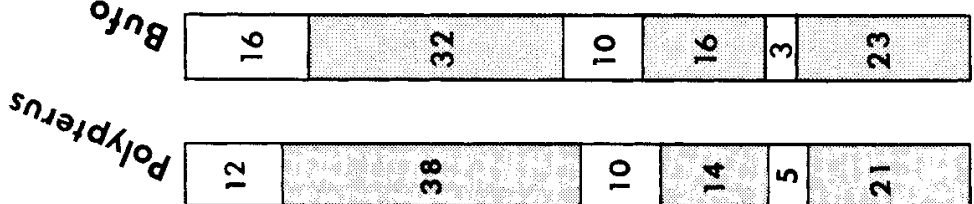

${ }^{040 / 5 / q u p}$

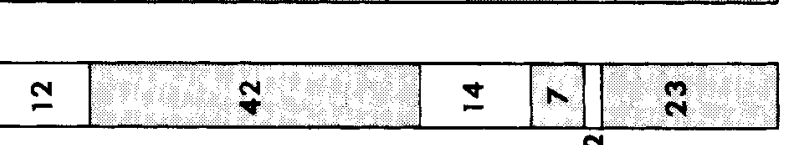

$\sin _{10} / 0^{\theta} N$
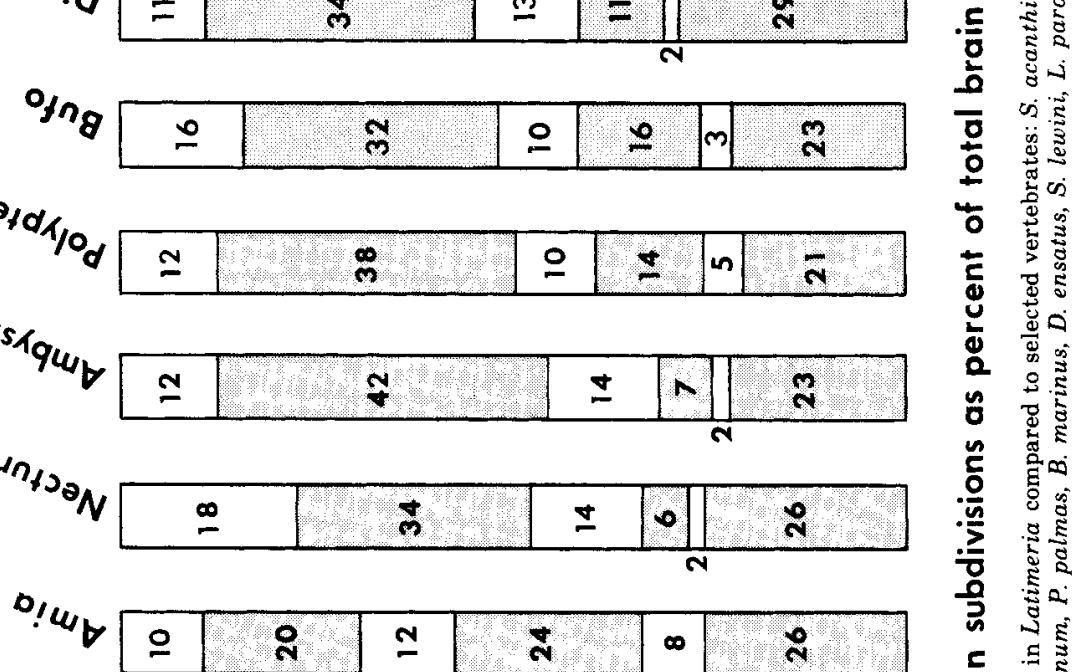

क ज

站

$\div$ 可

E

乌

\$

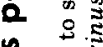

ช

c.

量 8

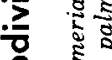

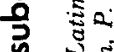

c $a$
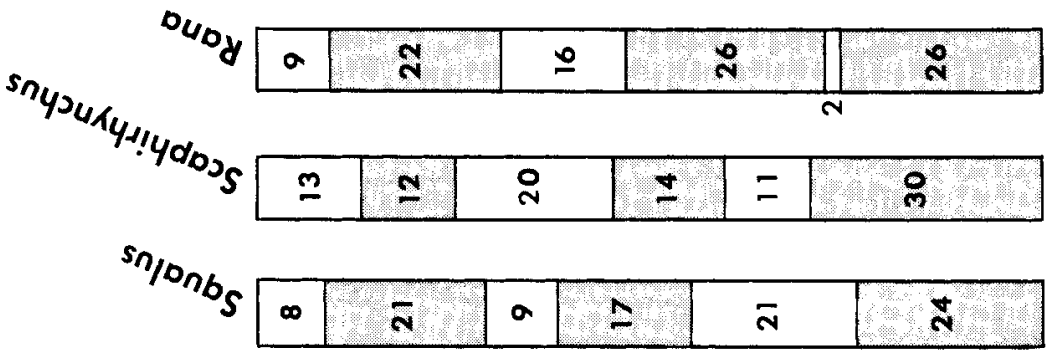

$0,104(10)$

\begin{tabular}{|l|l|l|l|l|l|}
\hline$m$ & 4 & $a$ & $=$ & 5 & $m$ \\
\hline
\end{tabular}

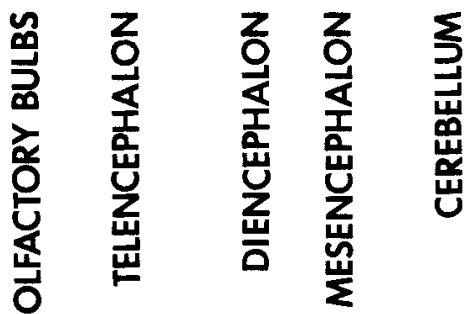

$\frac{5}{3}$ 
eralized sharks belonging to the families Squalidae and Hexanchidae (Daniel, '34). However, Latimeria is clearly unlike the advanced sharks such as Sphyrna (fig. 4). Latimeria can be characterized by an evaginated telencephalon and well developed visual and lateral line systems. However, the telencephalic pallium of Latimeria does not undergo an inversion as in land vertebrates (Niewenhuys, '69). Unlike most actinopterygians, Latimeria does not possess an elaborate optic tectum, but the tectum is better developed than in the neotenic salamanders, such as Ambystoma and Necturus, or the lepidosirenid lungfishes.

\section{Quantitative observations}

The data in figure 4 illustrate the relative size of major brain divisions among taxa, but they convey no information regarding the changes in absolute brain volume among taxa. Clearly the latter is an important measure of information processing in the central nervous system and thus a significant measure of brain evolution (Jerison, '73). Unfortunately, we still do not possess adequate information on the brain weight:body weight ratio of Latimeria. The most widely cited estimate is that reported by Millot and Anthony ('65) for their specimen C3, a $129-\mathrm{cm}, 40-\mathrm{kg}$ male, in which the fresh weight of the brain plus meninges did not exceed three grams. Our second specimen was a $30 \mathrm{~kg}$ male, and the preserved weight of the brain plus meninges and blood vessels was $2.68 \mathrm{~g}$. However, following removal of the meninges, blood vessels, and cranial nerves the brain weight of specimen two was only $0.62 \mathrm{~g}$. Since this brain specimen had obviously desiccated, brain specimen 3 was used to estimate a shrinkage correction factor. Estimates of this correction factor were based on: (1) the weight of brain specimen 3 with the meninges, blood vessels, and cranial nerves removed ( $1.13 \mathrm{gm})$; and (2) the combined weight of the cerebellum and medulla $(0.6901 \mathrm{gm})$. For the estimate, the weight of the missing brain parts was considered to equal, at most, the weight of the olfactory bulbs and diencephalon, i.e., $12 \%$ of the total brain weight (fig. 4). Thus, we arrived at an intact brain weight for specimen three of (1.13) $(12 / 88)+(1.13)=1.28 \mathrm{gm}$, giving an estimated correction factor of $(1.28) /(0.62)=$ 2.06. For the second estimate, we divided the combined weight of the cerebellum and medulla in brain specimen 3 by their weight in brain specimen 2 , arriving at a correction factor estimate of $(0.6901) /(0.3385)=2.04$. To simplify calculation, we rounded off both correction factors to 2.0 and multiplied all raw brain component weights of specimen 2 by this amount. Although specimen 3 was considerably smaller than specimen 2 or Millot and Anthony's specimen C3 $(85 \mathrm{~cm}$ vs. $128 \mathrm{~cm}$ and $129 \mathrm{~cm}$ ), a comparison of the dimensions of brain specimen 3 with the mid-sagittal photograph of the brain of Millot and Anthony's specimen C3 (Millot and Anthony, '65, Plate IV) showed only $0-10 \%$ differences.

The corrected weights of the major brain components of Latimeria are plotted and compared to those for other anamniotic vertebrates in figure 5 . While the body weight of Latimeria falls outside the range of the other plotted body weights, visual inspection indicates that the brain component weights of Latimeria are within an extrapolated range of those of many anamniotes. Further comparisons are difficult without numerical extrapolations, particularly if comparisons are attempted with specific anamniotic groups. Three specific numerical extrapolations are presented in figure 6 . The brain components of Latimeria are compared to a least-squares fitted line for the brain components of non-teleost actinopterygian fishes (fig. 6A), urodeles (fig. 6B), and anurans (fig. 6C). The slope (interspecific coefficient of allometry) and the coefficient of determination were calculated for each brain component line. These vertebrate groups were chosen for analysis since their brains show the greatest similarity to that of Latimeria. Lungfishes are not included as the present sample is inadequate.

All extrapolated brain components of nonteleost actinopterygians are larger than the corresponding brain components of Latimeria, with the exception of the telencephalon (fig. 6A). The telencephalon of Latimeria is as large as that of non-teleost actinopterygians, and our data support the observation of Nieuwenhuys ('69) that the pallium of Latimeria is greatly thickened and suggestive of the everted pallium of actinopterygians. The extrapolated cerebellum of non-teleost actinopterygians is far larger than that of Latimeria. In our sample of actinopterygians, the cerebellum exhibits a coefficient of allometry, disproportionate relative to that of other brain components, and this difference would be further exaggerated if teleosts 


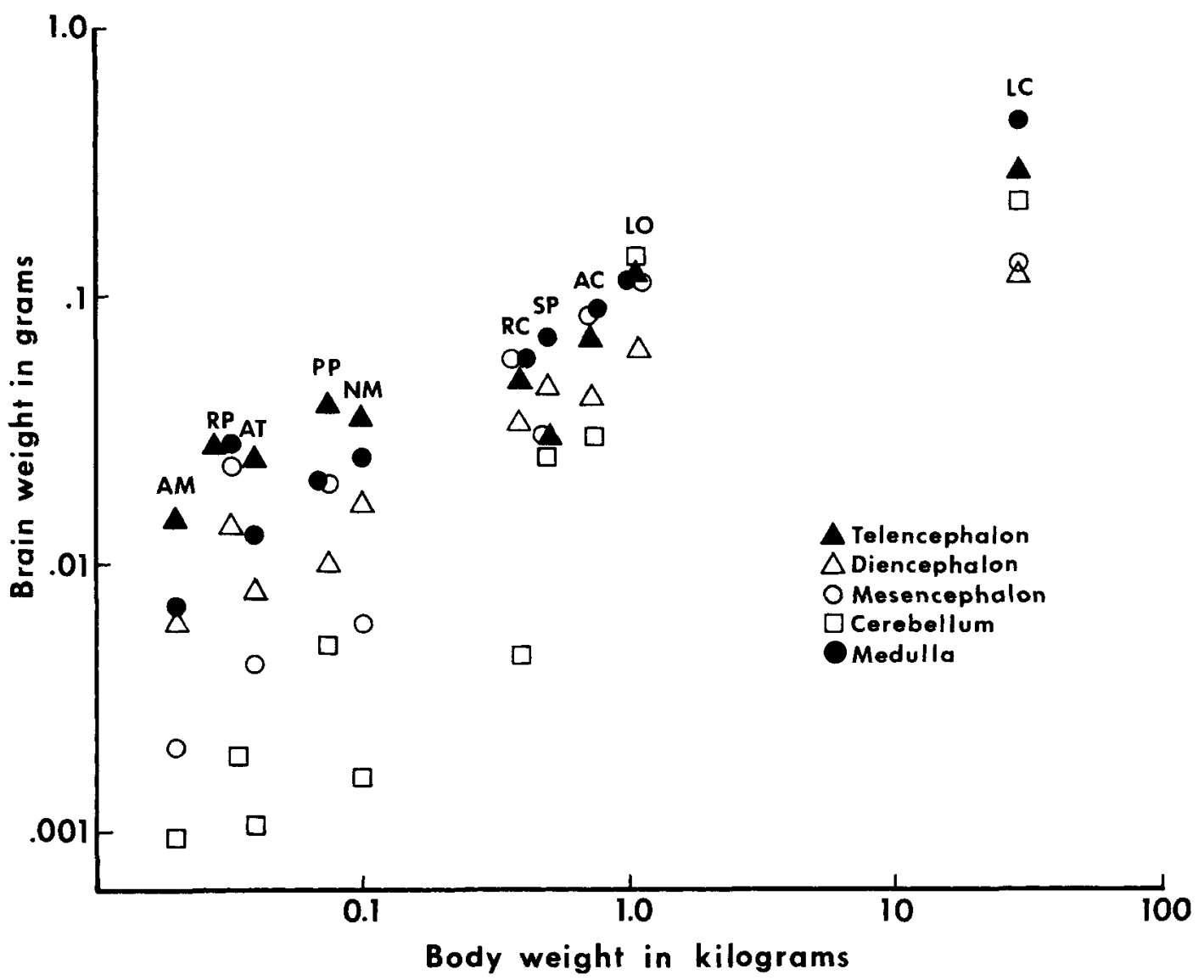

Fig. 5 Double log plots of major brain divisions and body weights for a number of anamniotic vertebrates and Latimeria. Am, Ambystoma maculatum; RP, Rana pipiens; AT, Ambystoma tigrinum; PP, Polypterus palmas; NM, Necturus maculosus; RC, Rana catesbeiana; SP, Scaphirhynchus platorynchus; AC, Amia calva: LO, Lepisosteus osseus; and LC, Latimeria chalumnae.

were included in the sample (unpublished observations).

The extrapolated telencephalic and medullar sizes of urodele amphibians are larger than the corresponding brain components of Latimeria (fig. 6B). The extrapolated diencephalon and mesencephalon of urodeles are only slightly smaller. However, the cerebellum of Latimeria is 29 to 30 times larger than the extrapolated cerebellum of urodeles.

The extrapolated mesencephalic size of anuran amphibians is larger than the corresponding brain component of Latimeria (fig. 6C). This difference is likely due to the hypertrophy of the visual system in anurans. The cerebellum $(6 \times)$, medulla $(2 \times)$, and telencephalon $(2 x)$ of Latimeria are larger than the corresponding extrapolated components of anurans. These differences in the rhombencephalon may be due, in part, to the development of the lateral line system. This system is well developed in Latimeria and absent in most adult amphibians. However, both $A m b y$. stoma and Necturus retain the lateralis system as adults (Herrick, '48), and thus differences may be, at best, related to the relative development of this system.

The relative sizes of brain components in amphibians and Latimeria are comparable, with the exception that the cerebellum of Latimeria is 6 to 30 times larger than that of amphibians.

\section{DISCUSSION}

Our analysis indicates that the brain of Latimeria possesses a number of characters 


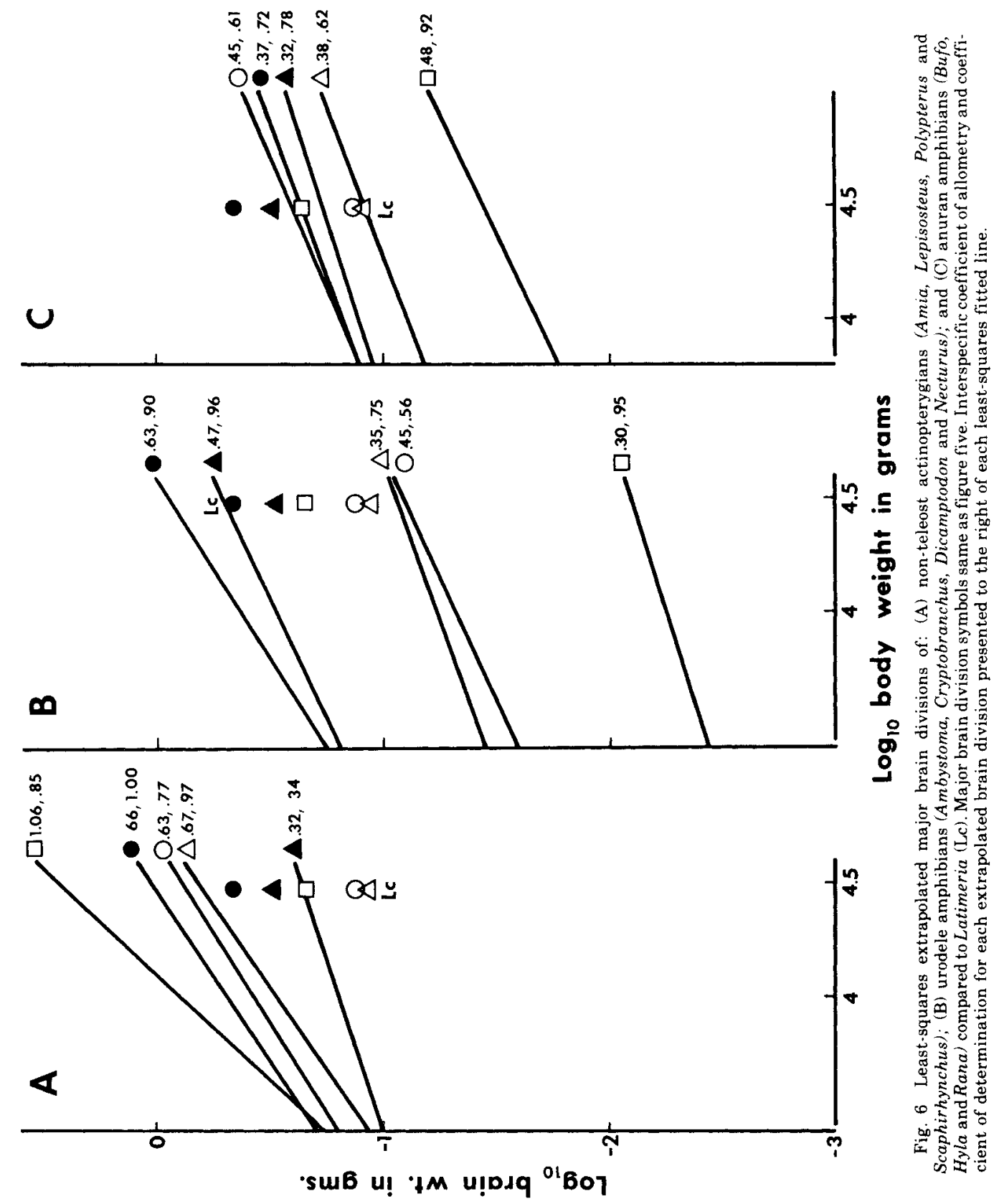


in common with those of Squalus and Scaphirhynchus. The latter taxa both exhibit relative brain proportions that are most similar to Latimeria. Scaphirhynchus deviates most by conspicuous hypertrophy of the olfactory apparatus and relative reduction in the visual system (unpublished observations). $L a$ timeria and the squaliform sharks possess well developed visual systems, lateral line organs, and moderate cerebellar development. Contrary to popular belief, sharks (with the exception of sphyrnids) are not characterized by hypertrophy of the olfactory system (Ebbesson, '72; Northcutt, '77b). Similarly, olfaction in Latimeria does not appear as well developed as vision, based on the relative size of the olfactory and optic tracts.

The following neural features characterize Latimeria; and they are probably primitive gnathostome features based on their wide distribution in squaliform sharks and non-teleost actinopterygian fishes: (1) moderate to poorly developed olfactory organs; (2) well developed visual system; (3) bilobed mesencephalic tectum with well developed internal lamination; (4) small mesencephalic acustico-lateralis center (torus semicircularis); (5) moderate to well developed cerebellum; (6) well developed lateral line organs supplied by two distinct and separate pairs of cranial nerves; and (7) an evaginated telencephalon. The last feature is not present in actinopterygian fishes, but is present in all other bony fishes, sharks, and agnathans; thus an evaginated telencephalon is most likely the primitive gnathostome condition.

Our data on the brain weight of Latimeria suggest that previous estimates are too high by a factor of two, and that errors were introduced by including the weight of the blood vessels, meninges, and parts of the peripheral cranial nerves.

Our calculated brain weight for Latimeria (1.1-1.5 gms) falls outside the predicted range for the brain weight: body weight ratios of other anamniotic vertebrates (Jerison, '73; Ebbesson and Northcutt, '76). However, Romer ('37) described the endocranial cavity of Ectosteorhachis, a late Carboniferous rhipidistian, and his reconstruction of the probable brain shape bears a number of remarkable similarities to that of Latimeria. More importantly, Jerison's ('73) volumetric analysis of the Ectosteorhachis endocast suggests that this rhipidistian would also possess a low brain weight: body weight ratio comparable to that of the sturgeon Scaphirhynchus. While Latimeria possesses a low brain weight: body weight ratio, these data suggest that such ratios may have generally characterized crossopterygians as well as primitive actinopterygians.

If the brain size of Latimeria is comparable to that of the crossopterygians that gave rise to amphibians, then virtually no increase in brain size would have occurred with the transition to the amphibian grade. The only absolute reduction in the size of any brain component would have been in the size of the cerebellum (figs. 4,6).

Detailed comparisons based on extrapolated lines suggest that most brain components in living actinopterygian fishes are larger than in Latimeria. The brain of Latimeria is more similar to the extrapolated amphibian brain components.

While such numerical manipulations are necessary to compare taxa with widely different weights, it must be remembered that these comparisons assume no change in selective pressures, except for changes related to size, and thus such extrapolations may be of limited value. Unfortunately, no other numerical comparative methods are presently available.

\section{ACKNOWLEDGMENTS}

We are deeply indebted to The Field Museum of Natural History, and Professors Karel Liem and Loren Woods, for making specimens from that institution available to us. We would also like to thank Professor J. Anthony of the University of Paris, and all those concerned with the international expedition who facilitated our receiving the brain of the captured specimen. We were fortunate to have available to us the talents of Mr. Donald Luce and Mrs. Elizabeth Reed for art work and histology respectively. This study was supported by NIH NS11006 and NSF GB-40134 research grants to RGN and NIH Fellowship 05293 to TJN.

\section{LITERATURE CITED}

Braford, Jr., M. R., and R. G. Northcutt 1974 Olfactory bulb projections in the bichir, Polypterus. J. Comp. Neur., 156: $165 \cdot 178$.

Clairambault, P., and E. Capanna 1973 Suggestions for a revision of the cytoarchitectonics of the telencephalon of Protopterus, Protopterus annectens (Owen). Boll. Zool. 40: $149-171$.

Daniel, J. F. 1934 The Elasmobranch Fishes. Third ed. University of California Press, Berkeley, 332 pp.

Ebbesson, S. O. E. 1972 New insights into the organization of the shark brain. Comp. Biochem. Physiol., 42A: 121.129. 
Ebbesson, S. O. E, and R. G. Northcutt 1976 Neurology of Anamniotic Vertebrates. In: Evolution of Brain and Behavior in Vertebrates. R. B. Masterton, M. E. Bitterman, C. B. G. Campbell and N. Hotton, eds. Lawrence Erlbaum Associates, Inc., $482 \mathrm{pp}$.

Goodrich, E. S. 1958 Studies on the Structure and Development of Vertebrates. 2 Vols. Dover Publications, Inc., New York, $837 \mathrm{pp}$.

Herrick, C. J. 1948 The Brain of the Tiger Salamander. The University of Chicago Press, $409 \mathrm{pp}$.

Holmgren, N., and C. J. van der Horst 1925 Contribution to the morphology of the brain of Ceratodus. Acta Zool., 6 : 59-165.

Jerison, H. J. 1973 Evolution of the Brain and Intelligence. Academic Press, New York, 482 pp.

Locket, N. A. 1973 Retinal structure in Latimeria chalumnae. Phil. Trans. Royal Soc. Lond., 266: 493-521.

Millot, J., and J. Anthony 1956 Considerations prélim. inaires sur le squelette axial et le système nerveux cen tral de Latimeria chalumnae Smith. Mem. Inst. Sci Madag., ser A, XI: 167-187.

1965 Anatomie de Latimeria chalumnae, t. II, Sys tème Nerveux et Organes des Sens. C.N.R.S., Paris, $130 \mathrm{pp}$.
1967 L'Organisation générale du prosencephale de Latimeria chalumnae Smith (Poisson crossopterygien coelacanthide). Evolution of the Forebrain. R. Hassler and H. Stephan, eds. Plenum Press, New York, pp. 50-60.

Nieuwenhuys, R. 1969 A survey of the structure of the forebrain in higher bony fishes. Ann. N. Y. Acad. Sci., 167: 31.64 .

Northcutt, R. G. 1977a Retinofugal projections in the lepidosirenid lungfishes. J. Comp. Neur., 174: 553-573.

$1977 \mathrm{~b}$ Elasmobranch central nervous system orga. nization and its possible evolutionary significance. Amer. Zool., 17: 411-429.

Northcutt, R. G., and T. J. Neary 1975 Observations on the optic tectum of the coelacanth, Latimeria chalumnae. Amer. Zool., 15: 806.

Romer, A. S. 1937 The braincase of the Carboniferous crossopterygian Megalichthys nitidus. Bull. Mus. Comp. Zool., Harvard Univ., 82: 1-73.

Schnitzlein, H. N., and E. C. Crosby 1968 The epithalamus and thalamus of the lungfish, Protopterus. J. f. Hirnforschung, 10: 351-371.

Thireau, M. 1976 L'encéphalisation chez les Urodeles. 1. Analyse volumetrizue de l'encéphale et de ses étages: recherche d'un lot d'especes de "base." Bull. Mus. natn. Hist. nat., Paris, 3e série, n 378, Zool., 266: 527-544. 